\title{
Possible involvement of CXC motif chemokine ligand 10 in exercise-induced collagen production of mouse dermal fibroblasts
}

\author{
Yuri Ishiuchi-Sato and Taku Nedachi \\ Graduate School of Life Sciences, Toyo University, Gunma 374-0193, Japan
}

\begin{abstract}
Evidence suggests that exercise can regulate skin functions such as promoting wound healing and inhibiting aging. Physical exercise modulates the secretion of proteins and peptides from skeletal muscles, called myokines, which play a role in transmitting exercise signals throughout the body. Therefore, exercise-regulated myokines may play a role in controlling skin functions; however, the precise mechanisms remain elusive. In this study, we focused on the recently identified CXC motif chemokine ligand 10 (CXCL10), an exercise-reduced myokine, and attempted to elucidate its role in regulating collagen synthesis in dermal fibroblasts. Mouse $\mathrm{C} 2 \mathrm{C} 12$ myotubes were stimulated with or without electrical pulse stimulation (EPS) to induce contraction for $24 \mathrm{~h}$, and conditioned medium was collected (EPS-CM or Ctrl-CM, respectively). The reduction in CXCL10 concentration by EPS was confirmed using ELISA. Next, mouse dermal fibroblasts were isolated from the dorsal skin of C57BL6/J mice (2 weeks old) and were stimulated with Ctrl-CM or EPS-CM for $24 \mathrm{~h}$. EPS-CM treatment significantly increased collagen production compared to Ctrl-CM treatment. Even in the Ctrl-CM condition, the addition of an antagonist for CXCR3 (CXCL10 receptor) increased collagen production. In contrast, recombinant CXCL10 abolished EPS$\mathrm{CM}$-dependent collagen induction. Overall, this study raises the possibility that CXCL10 secretion from skeletal muscles may control collagen production in mouse dermal fibroblasts.
\end{abstract}

Key words: Skeletal muscle, Myokines, Exercise, Mouse dermal fibroblasts

PHYSICAL EXERCISE modulates skeletal musclederived peptides and proteins, termed myokines $[1,2]$. Some of these myokines are believed to send exercise signals to other tissues/organs, thereby regulating exercise-dependent adaptive processes in the whole body [3-5]. For example, the secretion and expression of interleukin-6 (IL-6), one of the earliest identified myokines, from skeletal muscles is increased by exercise [6], followed by regulation of glucose incorporation into skeletal muscles [7] and enhancing insulin action to synthesize glycogen [8]. Although various exercisedependent myokines have been newly identified [9-11], their physiological functions remain elusive. Therefore, one of the major goals of myokine research is to estimate and identify their precise roles in exercise-regulated physiological changes.

We have identified several proteins as novel exercise-

Submitted Apr. 28, 2021; Accepted May 27, 2021 as EJ21-0275 Released online in J-STAGE as advance publication Jul. 14, 2021 Correspondence to: Taku Nedachi, Graduate School of Life Sciences, Toyo University, 1-1-1 Izumino, Itakura-machi, Oura-gun, Gunma 374-0193, Japan.

E-mail: nedachi@toyo.jp regulated myokines using an in vitro contractile model composed of $\mathrm{C} 2 \mathrm{C} 12$ myotubes and electrical pulse stimulation (EPS) [12-15]. C-X-C motif chemokine ligand 10 (CXCL10), also known as interferon gammainduced protein 10 (IP-10), is a newly identified myokine whose expression is reduced due to muscle contraction [14]. CXCL10 is secreted from monocytes and endothelial cells in response to interferon-gamma (IFN $\gamma$ ) or tumor necrosis factor-alpha (TNF $\alpha$ ) [16]. CXCL10 exerts chemotaxic activity on monocytes and T lymphocytes [17] and contributes to the activation of $\mathrm{T}$ and B lymphocytes, natural killer cells, dendritic cells, and macrophages $[18,19]$. Moreover, CXCL10 possesses potent angiostatic activity by promoting apoptosis of endothelial cells [20], which may contribute to its anti-tumor activity [21, 22]. It can be speculated that as CXCL10 is multifunctional, the reduction of CXCL10 from skeletal muscle through exercise may have a wide range of effects on the whole body.

Recent studies have strongly suggested that physical exercise regulates skin function. One example is the relationship between exercise and cutaneous wound healing. It has been shown that forced treadmill running in rats or 
endurance training in mice significantly alters cutaneous wound healing processes [23, 24]. A similar line of evidence was provided by studies using obesity models displaying delayed wound healing, skin thinning, and reduction of collagen synthesis [25], all of which were attenuated by physical exercise [25]. Moreover, exercise may lower cancer risk by inhibiting insulin-like growth factor-1 (IGF-1) signals [26, 27]. In a skin cancer model, exercise appears to activate $\mathrm{p} 53$, followed by induction of $\mathrm{p} 21$, insulin-like growth factor-binding protein 3 (IGFBP3), and phosphatase and tensin homolog (PTEN), which results in a reduction of IGF-1 signals [27]. More recently, it has been reported that interleukin-15 (IL-15), which is secreted from skeletal muscles, is upregulated by exercise and may improve aging-related collagen reduction and decreased mitochondrial activity in mouse dermis $[23,28]$. However, the involvement of myokines other than IL-15 in regulating exercise-dependent cutaneous function have not yet been clarified.

In this study, we investigated the effect of exercisedependent myokines on cutaneous functions, with particular focus on the exercise-reduced myokine CXCL10.

\section{Materials and Methods}

All experiments using animals were approved by the Animal Care Committee at Toyo University. Male C57BL6/J mice (8 weeks old) (Charles-River Japan, Inc., Kanagawa, Japan) were individually housed in a temperature-controlled room. Mice were fed chow (Nosan Corporation, Kanagawa, Japan) and provided with water ad libitum, and were acclimatized to a $12 \mathrm{~h}$ light cycle. The mice were subjected to forced treadmill running. (15 cm/s for $30 \mathrm{~min}$ ). After treadmill running, the mice were anesthetized and sacrificed immediately. An area of approximately $6.0 \mathrm{~cm}^{2}(3.0 \times 2.0 \mathrm{~cm})$ was shaved on the back of each mouse with electric clippers, and approximately $2.0 \mathrm{~cm}^{2}(2.0 \times 1.0 \mathrm{~cm})$ of whole dorsal skin was collected.

\section{Cell culture}

Mouse skeletal muscle cell line $\mathrm{C} 2 \mathrm{C} 12$ cells were maintained in growth medium (Dulbecco's modified Eagle medium (DMEM) low glucose (LG; $1.0 \mathrm{~g} / \mathrm{L}$ ) (Nacalai Tesque, Kyoto, Japan) $+10 \%$ fetal bovine serum (FBS) (Biowest, Nuaillé, France) $+1 \%$ penicillinstreptomycin mixed solution (Nacalai Tesque)) in a $75 \mathrm{~cm}^{2}$ flask (Corning, NY, USA). Cells were cultured at $37^{\circ} \mathrm{C}$ under a $5 \% \mathrm{CO}_{2}$ atmosphere. The medium was changed every 48 h. For all experiments, C2C12 myoblasts were seeded into 8 well- plates (Thermo Fisher Scientific, Waltham, MA, USA) with $2 \mathrm{~mL}$ of growth medium. When $\mathrm{C} 2 \mathrm{C} 12$ cells reached $100 \%$ confluency, differentiation was induced by changing to differentiation medium (DMEM high glucose ( $\mathrm{HG} ; 4.5 \mathrm{~g} / \mathrm{L})$ (Nacalai Tesque) $+2 \%$ calf serum (Biowest) $+1 \%$ penicillin-streptomycin mixed solution). The medium was replaced every $24 \mathrm{~h}$. Induction of differentiation was performed for approximately 10 days until myotubes were formed.

Mouse dermal fibroblasts were isolated from the dorsal skin of the mice. Mice (2 weeks old) were euthanized by cervical dislocation. The dorsal skin was cut to $10 \mathrm{~mm}^{2}$ and stuck on a 6 well-plate (Corning). After drying, $2 \mathrm{~mL}$ of media (Minimum Essential Medium Eagle (Thermo Fisher Scientific) $+10 \%$ FBS (Biowest) $+1 \%$ penicillin-streptomycin (Nacalai Tesque) $+1 \%$ MEM Non-Essential Amino Acids Solution (100X) (Nacalai Tesque) $+1 \%$ sodium pyruvate solution (100X) (Nacalai Tesque)) were added. Approximately 10 days later, fibroblasts that had migrated to the peripheral parts of mouse dorsal skin slices were collected using TrypLE ${ }^{\text {TM }}$ Express (1X) (Thermo Fisher Scientific) and seeded in $75 \mathrm{~cm}^{2}$ flasks (Corning) with growth medium.

\section{Electrical pulse stimulation (EPS)}

Differentiated $\mathrm{C} 2 \mathrm{C} 12$ myotubes were cultured in an 8 well-plate and placed in a chamber for electrical pulse stimulation (C-Dish; IonOptix, Milton, MA, USA). EPS (20 V/30 mm, $1 \mathrm{~Hz}, 2 \mathrm{~ms}$ ) was applied to the myotubes using a C-Pace Pulse generator (C-Pace 100; IonOptix). After incubation with EPS for $24 \mathrm{~h}$, the culture supernatants were collected.

\section{Real-time qPCR}

RNA from cells or tissues was isolated using TRIzol ${ }^{\circledR}$ reagent (Thermo Fisher Scientific) according to the manufacturer's protocol, and the concentration was quantified using Nanodrop ${ }^{\text {TM }}$ 2000/2000c (Thermo Fisher Scientific). Reverse transcription was performed using ReverTraAce ${ }^{\circledR}$ RNA (Macherey-Nagel, Düren, Germany) according to the manufacturer's protocol. Quantitative PCR was performed using the KAPA SYBR FAST qPCR Kit Master Mix (2X) ABI Prism ${ }^{\text {TM }}$ (Kapa Biosystems, Boston, MA, USA) with the following primer sets: mouse Gapdh, 5'-TGT GTC CGT CGT GGA TCT GA-3' and 5'-CGT GCT TCA CCA CCT TCT TGA-3', and mouse Collal, 5'-GCC AAG AAG ACA TCC CTG AAG-3' and 5'-TGT GGC AGA TAC AGA TCA AGC-3'.

\section{Measurement of collagen secretion}

Mouse dermal fibroblasts were treated with the conditioned medium obtained from $\mathrm{C} 2 \mathrm{C} 12$, stimulated with or without electrical pulse, in the presence or absence of CXCR3 antagonists (NBI74330, TOCRIS Bioscience, 
Bristol, United Kingdom). Collagen secretion from dermal fibroblasts was analyzed using the Sirius Red Collagen Detection Kit (Chondrex, Inc., Redmond, WA, USA). In brief, the culture supernatant of dermal fibroblasts was concentrated, and Sirius Red solution was added to the concentrated samples and collagen standards $(500,250,125,63,31.5,16$, and $8 \mu \mathrm{g} / \mathrm{mL})$; it was then incubated at room temperature for $30 \mathrm{~min}$. The absorbance of each reaction was measured using $\mathrm{xMark}^{\mathrm{TM}}$ microplate spectrophotometer (Bio-Rad, Hercules, CA, USA).

\section{Statistical analysis}

All experiments were repeated at least three times. Statistical analyses were performed using GraphPad Prism (GraphPad Software, CA, USA). Student's $t$-test or one-way analysis of variance (ANOVA) followed by Tukey's post-hoc test was used. Differences were considered significant at $* p<0.05$.

\section{Results and Discussion}

The metabolism of collagen is accelerated by physical training in young mice [29]. The effect of physical exercise is not limited to regulating collagen synthesis, as it also regulates collagen degradation by controlling the expression of matrix metalloproteinases and their inhibitors [30]. More recently, Safder et al. demonstrated that endurance exercise suppressed thinning of the dermis in polymerase-gamma mutator mice [31]. Overall, reports strongly suggest that physical exercise has the potential to control the collagen content in connective tissues.

To confirm whether a single bout of exercise in mice regulates collagen expression in the skin, we used a forced treadmill running model, as previously described $[14,32]$. Forced exercise significantly increased Collal gene expression in the dorsal skin by approximately $3.5-$ fold compared to the sedentary control $(* p<0.05, n=$ $5-6, t$-test) (Fig. 1). These results suggested that a single bout of forced exercise in mice was sufficient to induce Collal expression in the skin.

Next, we investigated whether contraction-dependent alteration of myokine profiles in $\mathrm{C} 2 \mathrm{C} 12$ cells affects collagen expression and secretion in dermal fibroblasts. Mouse dermal fibroblasts isolated from 2-week-old mice were treated with culture supernatants from $\mathrm{C} 2 \mathrm{C} 12$ myotubes, stimulated with or without EPS for $24 \mathrm{~h}$ (EPS-CM and Ctrl-CM, respectively; see Fig. 2A). Collagen secretion was significantly induced by EPS-CM compared with Ctrl-CM (mean \pm SEM: Ctrl-CM, $9.8 \pm 1.3 \mu \mathrm{g} / \mathrm{mL}$; EPS-CM, $15.2 \pm 1.6 \mu \mathrm{g} / \mathrm{mL}$ ) (Fig. $2 \mathrm{~B}, * p<0.05, n=5$, $t$-test). In addition, EPS-CM enhanced Collal gene expression by approximately 1.5 -fold compared to Ctrl-

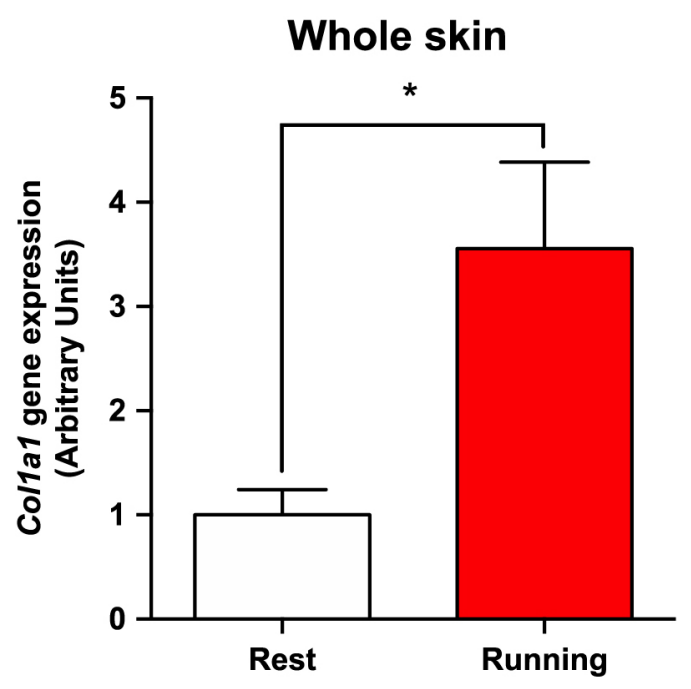

Fig. 1 A single bout of exercise increases Collal expression in mouse dorsal skin. Male C57BL/6 mice were divided into a sedentary group and an exercise group. Exercise group underwent forced treadmill running for $30 \mathrm{~min}$. Gene expression of Collal in the dorsal skin was analyzed by qPCR. The gene expression levels were normalized by Gapdh gene expression. The graphs represent mean \pm SEM ( $* p<0.05, n=5-6)$.

CM (Fig. 2C, * $p<0.05, n=5, t$-test). These results suggest that collagen production in fibroblasts is regulated by EPS-regulated secreted factor(s), possibly myokine(s).

Several myokines are induced or reduced by EPS in C2C12 cells [12-15]. Of these, CXCL10 is implicated in the regulation of several skin functions. For example, cyclic GMP-AMP (cGAMP) promotes skin wound healing, which is mediated by CXCL10 secretion [33]. In addition, the CXCL10 receptor CXCR3 is expressed in both epidermal cells and dermal fibroblasts to regulate cell migration [34]. Moreover, high glucose or transforming growth factor- $\beta$ induced collagen production in $\mathrm{NIH} / 3 \mathrm{~T} 3$ cells, which was significantly attenuated by administration of recombinant CXCL10 [35]. These results allowed us to hypothesize that the reduction of CXCL10 in EPS-CM contributes to enhancing collagen production in fibroblasts.

The reduction in CXCL10 concentration in EPS-CM was confirmed by ELISA (Fig. 3A, $* p<0.05, n=3, t$ test), and the expression of myokine-related receptors was quantified by qPCR. After demonstrating that EPS induced CXCL1 and CXCL5, whereas reduced CXCL10 and CCL5 secretion from $\mathrm{C} 2 \mathrm{C} 12$ cells [13-15], we analyzed the corresponding receptors (CXCR2 for CXCL1 and CXCL5; CCR1, 3, and 5 for CCL5; CXCR3 for CXCL10). CCR1, CXCR2, and CXCR3 were observed in the mouse fibroblasts (Fig. 3B).

To elucidate the potential involvement of the CXCR3 and CXCL10 receptors on collagen production in dermal 

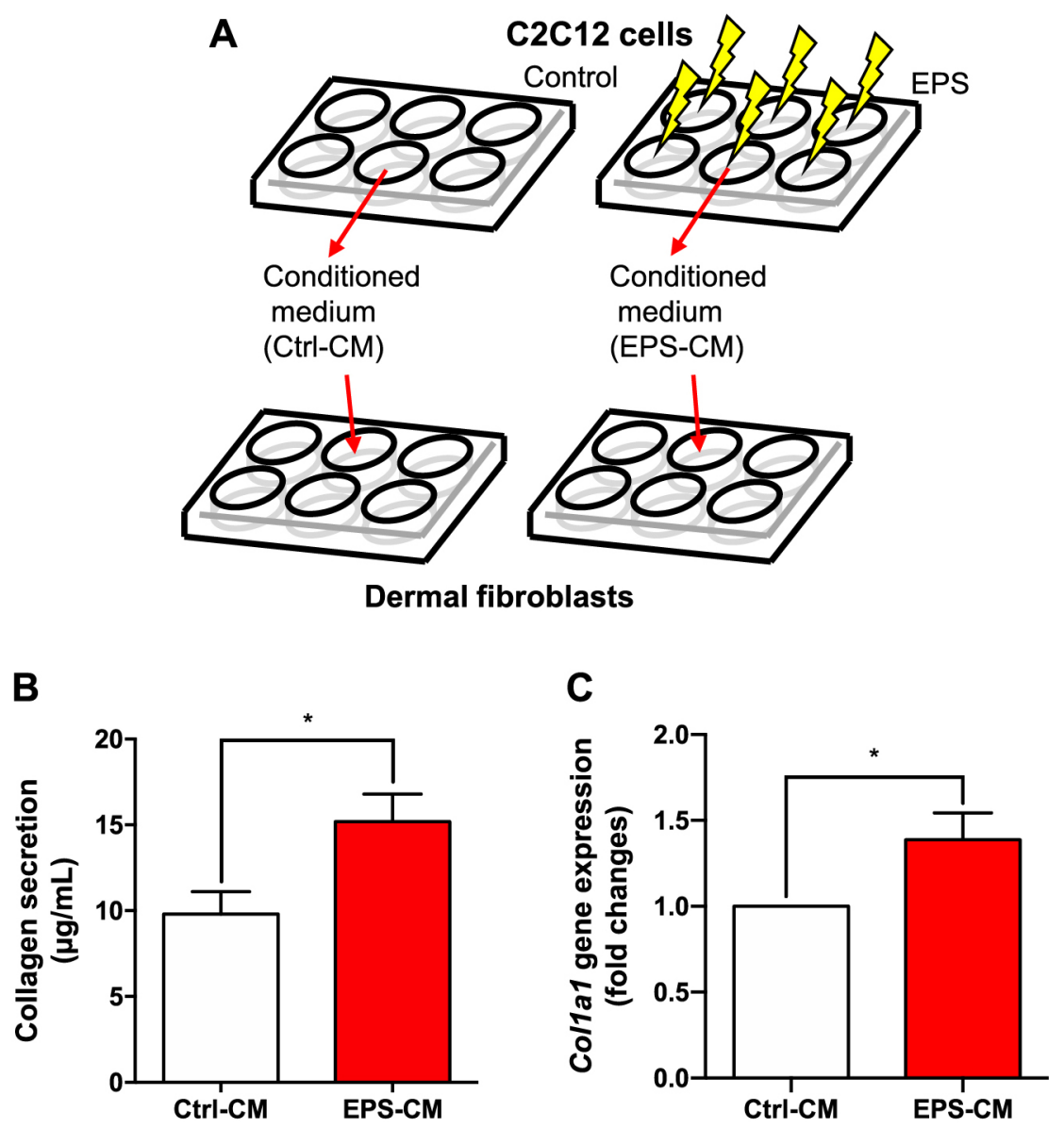

Fig. 2 Effects of EPS-dependent changes of myokine secretion on mouse dermal fibroblasts. (A-C) Mouse C2C12 myotubes were incubated with or without electrical pulse stimulation (EPS) for $24 \mathrm{~h}$, followed by collecting conditioned medium (EPS-CM or Ctrl-CM, respectively). Dermal fibroblasts were isolated and treated with either EPS-CM or Ctrl-CM for 24 hours (See (A) for more details). (B) Collagen production from fibroblasts was analyzed by Sirius red collagen detection kit. The graphs represent mean \pm SEM $(*: p<0.05, n=5)$. (C) Collal gene expression was analyzed by qPCR. The graphs represent mean $\pm \operatorname{SEM}(* p<$ $0.05, n=5)$.

fibroblasts, we tested the effect of a CXCR3 antagonist NBI74330. Mouse dermal fibroblasts were treated with Ctrl-CM, which contained substantial amounts of CXCL10, in the presence of $0-30 \mathrm{ng} / \mathrm{mL}$ of $( \pm)$ NBI74330. After $24 \mathrm{~h}$ of incubation, the collagen concentration in the culture supernatants was measured. As shown in Fig. 3C, $30 \mathrm{ng} / \mathrm{mL}$ of NBI74330 treatment induced collagen concentration (Ctrl, $10.1 \pm 1.3 \mu \mathrm{g} / \mathrm{mL}$; $30 \mathrm{ng} / \mathrm{mL}$ NBI74330, $17.6 \pm 2.8 \mu \mathrm{g} / \mathrm{mL}$ ) (Fig. $3 \mathrm{C}, * p<$ $0.05, n=3$, ANOVA), indicating that the attenuation of CXCR3 signaling induced collagen secretion in dermal fibroblasts.

We also examined whether administration of recombinant CXCL10 (rCXCL10) abolished EPS-CM-dependent collagen production. Dermal fibroblasts were treated with Ctrl-CM, EPS-CM, or EPS-CM supplemented with rCXCL10 $(25 \mathrm{pg} / \mathrm{mL})$, and collagen concentration was measured. As shown in Fig. 3D, the addition of recombinant CXCL10 (rCXCL10) partially abolished the EPS-
$\mathrm{CM}$ dependent collagen production, whereas did not affect Ctrl-CM dependent collagen production (Fig. 3D, Ctrl-CM, $9.6 \pm 0.6 \mu \mathrm{g} / \mathrm{mL}$; Ctrl-CM with rCXCL10, 10.1 $\pm 1.1 \mu \mathrm{g} / \mathrm{mL}$; EPS-CM, $16.4 \pm 1.5 \mu \mathrm{g} / \mathrm{mL}$; EPS-CM with

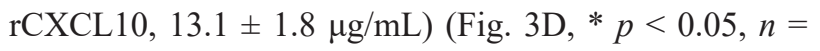
5-9, ANOVA). These results suggest that EPS-dependent CXCL10 reduction in EPS-CM attenuates CXCR3 signaling in dermal fibroblasts and may, in turn, contribute to EPS-CM-induced collagen production in dermal fibroblasts.

To our knowledge, IL-15 is the only reported exerciseregulated myokine that regulates collagen synthesis in the skin [28]. Although further studies are required, we propose that exercise-dependent alteration of CXCL10 secretion from skeletal muscles may also control collagen production in the dermis. We also noted other exercise-regulated myokines, which may be involved in regulating skin functions. Decorin, a small leucine-rich proteoglycan, was identified as an exercise-induced 
A

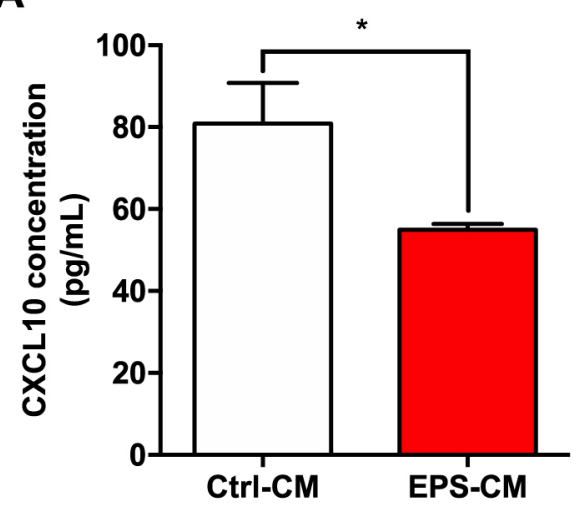

C

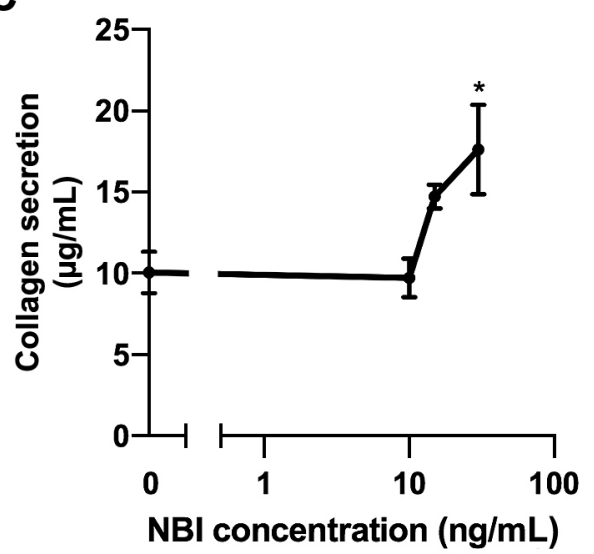

B

\begin{tabular}{|c|c|c|}
\hline 1 & 3 & 6 \\
\hline 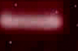 & & $\therefore$ \\
\hline Lane & Receptor & Expression \\
\hline 1 & CCR1 & + \\
\hline 2 & CCR2 & - \\
\hline 3 & CCR3 & - \\
\hline 4 & CCR5 & - \\
\hline 5 & CXCR2 & + \\
\hline 6 & CXCR3 & + \\
\hline
\end{tabular}

D

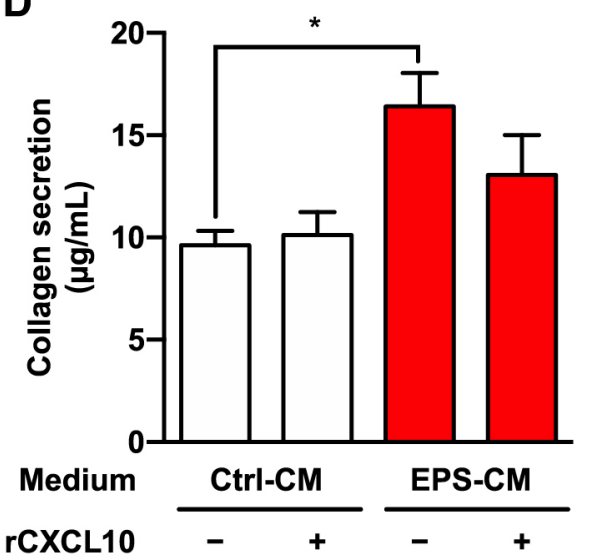

Fig. 3 EPS-CM dependent attenuation of CXCL10-CXCR3 signaling contributes to increased collagen production in mouse dermal fibroblasts. (A) Mouse C2C12 myotubes were incubated with or without electrical pulse stimulation (EPS) for 24 h, followed by collecting conditioned medium (EPS-CM or Ctrl-CM, respectively). CXCL10 levels were analyzed by ELISA $(* p<0.05, n=3$ ). (B) The expression of each chemokine receptor was analyzed by PCR. (C) Mouse dermal fibroblasts were treated with Ctrl-CM for $24 \mathrm{~h}$ in the presence of different concentration of $\mathrm{NBI} 74330(0,10,20$, and $30 \mathrm{ng} / \mathrm{mL})$. Collagen production was analyzed as described ( $* p<0.05, n=3$ ). (B) Mouse dermal fibroblasts were treated with Ctrl-CM or EPS-CM in the presence of recombinant CXCL10 (rCXCL10; $25 \mathrm{pg} / \mathrm{mL})$. Again, collagen production was analyzed as described $(* p<0.05, n=5-9)$. All graph represents mean \pm SEM.

myokine [36] and has the capacity to bind collagen, which is believed to regulate collagen fibrillogenesis and the final diameter of fibrils [37]. Another myokine, CXCL12, also known as stromal cell-derived factor 1 (SDF-1), is also upregulated by physical exercise [38] and accelerates skin wound healing [39].

In addition to physical exercise, obesity has a considerable role in dermal connective tissues. For example, obesity-associated enlarged adipocytes secrete more free fatty acids (FFAs) [40], and the elevation of FFAs reduces Collal gene expression in NIH/3T3 cells [41]. Lörincz recently reported that voluntary exercise in mice improved obesity-dependent thinning of the dermis associated with the reduction of collagen density [25]. Moreover, we recently reported that CXCL10 secretion from skeletal muscles was induced when mice were given a high-fat diet for 10 weeks [42]. Therefore, the exercise- dependent reduction of the myokine CXCL10 may have a role in attenuating the obesity-dependent inhibition of collagen synthesis.

In conclusion, our present study raised the possibility that CXCL10 secretion from skeletal muscles controls collagen production in mouse dermal fibroblasts. Although it remains possible that the exercise directly stimulates the skin and increases the expression of collagen, the exercise-dependent CXCL10 reduction in skeletal muscle may, in part, contribute to exercise-induced regulation of skin function.

\section{Acknowledgement}

We thank Dr. Jérôme Lamartine (Université Claude Bernard Lyon 1, France), Dr. Keitaro Yamanouchi, and Dr. Takashi Matsuwaki (University of Tokyo, Japan) for 
their helpful comments. We also thank Ms. Ayano Yoshikawa for providing excellent technical assistance. This work was partially supported by a Grant-in-Aid for Scientific Research (C) \#19K06442 to T.N. and Grantin-Aid for JSPS Fellows \#19J10894 to Y.I-S. from the Japan Society for the Promotion of Science (JSPS).

\section{Disclosure}

The authors have no conflicts of interest to declare.

\section{Authors' Contributions}

Y.I-S. and T.N. designed the study. Y.I-S. performed the experiments and analyzed the data. Y.I-S. and T.N. wrote the manuscript. Both authors read and approved the final manuscript.

\section{References}

1. Leal LG, Lopes MA, Batista ML Jr (2018) Physical exercise-induced myokines and muscle-adipose tissue crosstalk: a review of current knowledge and the implications for health and metabolic diseases. Front Physiol 9: 1307.

2. Son JS, Chae SA, Testroet ED, Du M, Jun HP (2018) Exercise-induced myokines: a brief review of controversial issues of this decade. Expert Rev Endocrinol Metab 13: $51-58$.

3. Knudsen SH, Pedersen BK (2015) Targeting inflammation through a physical active lifestyle and pharmaceuticals for the treatment of type 2 diabetes. Curr Diab Rep 15: 82.

4. Argilés JM, López-Soriano J, Almendro V, Busquets S, López-Soriano FJ (2005) Cross-talk between skeletal muscle and adipose tissue: a link with obesity? Med Res Rev 25: 49-65.

5. Frydelund-Larsen L, Penkowa M, Akerstrom T, Zankari A, Nielsen S, et al. (2007) Exercise induces interleukin-8 receptor (CXCR2) expression in human skeletal muscle. Exp Physiol 92: 233-240.

6. Jonsdottir IH, Schjerling P, Ostrowski K, Asp S, Richter EA, et al. (2000) Muscle contractions induce interleukin-6 mRNA production in rat skeletal muscles. $J$ Physiol 528 Pt 1: 157-163.

7. Helge JW, Stallknecht B, Pedersen BK, Galbo H, Kiens B, et al. (2003) The effect of graded exercise on IL-6 release and glucose uptake in human skeletal muscle. $J$ Physiol 546: 299-305.

8. Pedersen BK, Steensberg A, Fischer C, Keller C, Keller P, et al. (2003) Searching for the exercise factor: is IL-6 a candidate? J Muscle Res Cell Motil 24: 113-119.

9. Høier B, Olsen K, Nyberg M, Bangsbo J, Hellsten Y (2010) Contraction-induced secretion of VEGF from skeletal muscle cells is mediated by adenosine. Am J Physiol Heart Circ Physiol 299: H857-H862.

10. Seldin MM, Peterson JM, Byerly MS, Wei Z, Wong GW (2012) Myonectin (CTRP15), a novel myokine that links skeletal muscle to systemic lipid homeostasis. J Biol Chem 287: 11968-11980.

11. Aoi W, Naito Y, Takagi T, Tanimura Y, Takanami Y, et al. (2013) A novel myokine, secreted protein acidic and rich in cysteine (SPARC), suppresses colon tumorigenesis via regular exercise. Gut 62: 882-889.

12. Nedachi T, Fujita H, Kanzaki M (2008) Contractile C2C12 myotube model for studying exercise-inducible responses in skeletal muscle. Am J Physiol Endocrinol Metab 295: E1191-E1204.

13. Nedachi T, Hatakeyama H, Kono T, Sato M, Kanzaki M (2009) Characterization of contraction-inducible CXC chemokines and their roles in $\mathrm{C} 2 \mathrm{C} 12$ myocytes. $\mathrm{Am} \mathrm{J}$ Physiol Endocrinol Metab 297: 866-878.

14. Ishiuchi $\mathrm{Y}$, Sato $\mathrm{H}$, Tsujimura $\mathrm{K}$, Kawaguchi $\mathrm{H}$, Matsuwaki T, et al. (2018) Skeletal muscle cell contraction reduces a novel myokine, chemokine (C-X-C motif) ligand 10 (CXCL10): potential roles in exercise-regulated angiogenesis. Biosci Biotechnol Biochem 82: 97-105.

15. Ishiuchi $Y$, Sato H, Komatsu N, Kawaguchi H, Matsuwaki $\mathrm{T}$, et al. (2018) Identification of CCL5/RANTES as a novel contraction-reducible myokine in mouse skeletal muscle. Cytokine 108: 17-23.

16. Antonelli A, Ferrari SM, Giuggioli D, Ferrannini E, Ferri C, et al. (2014) Chemokine (C-X-C motif) ligand (CXCL) 10 in autoimmune diseases. Autoimmune Rev 13: 272280.

17. Lahrtz F, Piali L, Nadal D, Pfister HW, Spanaus KS, et al. (1997) Chemotactic activity on mononuclear cells in the cerebrospinal fluid of patients with viral meningitis is mediated by interferon-gamma inducible protein-10 and monocyte chemotactic protein-1. Eur J Immunol 27: 2484-2489.

18. Dufour JH, Dziejman M, Liu MT, Leung JH, Lane TE, et al. (2002) IFN-gamma-inducible protein 10 (IP-10; CXCL10)- deficient mice reveal a role for IP-10 in effector $\mathrm{T}$ cell generation and trafficking. $J$ Immunol 168 : 3195-3204.

19. Zhang X, Fan L, Wu J, Xu H, Leung WY, et al. (2019) Macrophage p38a promotes nutritional steatohepatitis through M1 polarization. $J$ Hepatol 71: 163-174.

20. Bodnar RJ, Yates CC, Wells A (2006) IP-10 blocks vascular endothelial growth factor-induced endothelial cell motility and tube formation via inhibition of calpain. Circ Res 98: 617-625.

21. Feldman AL, Friedl J, Lans TE, Libutti SK, Lorang D, et al. (2002) Retroviral gene transfer of interferon-inducible 
protein 10 inhibits growth of human melanoma xenografts. Int J Cancer 99: 149-153.

22. Sun Y, Finger C, Alvarez-Vallina L, Cichutek K, Buchholz CJ (2005) Chronic gene delivery of interferoninducible protein 10 through replication-competent retrovirus vectors suppresses tumor growth. Cancer Gene Ther 12: 900-912.

23. Wong W, Crane ED, Kuo Y, Kim A, Crane JD (2019) The exercise cytokine interleukin-15 rescues slow wound healing in aged mice. J Biol Chem 294: 20024-20038.

24. Saguie BO, Romana-Souza B, Martins RL, Monte-AltoCosta A (2017) Exercise prior to, but not concomitant with, stress reverses stress-induced delayed skin wound healing. Wound Repair Regen 25: 641-651.

25. Lörincz K, Haluszka D, Kiss N, Gyöngyösi N, Bánvölgyi A, et al. (2017) Voluntary exercise improves murine dermal connective tissue status in high-fat diet-induced obesity. Arch Dermatol Res 309: 209-215.

26. Lu YP, Lou YR, Nolan B, Peng QY, Xie JG, et al. (2006) Stimulatory effect of voluntary exercise or fat removal (partial lipectomy) on apoptosis in the skin of UVB lightirradiated mice. Proc Natl Acad Sci USA 103: 1630116306.

27. Yu M, King B, Ewert E, Su X, Mardiyati N, et al. (2016) Exercise activates $\mathrm{p} 53$ and negatively regulates IGF-1 pathway in epidermis within a skin cancer model. PLoS One 11: $\mathrm{e} 0160939$.

28. Crane JD, MacNeil LG, Lally JS, Ford RJ, Bujak AL, et al. (2015) Exercise-stimulated interleukin-15 is controlled by AMPK and regulates skin metabolism and aging. Aging Cell 14: 625-634.

29. Suominen H, Kiiskinen A, Heikkinen E (1980) Effects of physical training on metabolism of connective tissues in young mice. Acta Physiol Scand 108: 17-22.

30. Koskinen SO, Heinemeier KM, Olesen JL, Langberg H, Kjaer M (2004) Physical exercise can influence local levels of matrix metalloproteinases and their inhibitors in tendon-related connective tissue. J Appl Physiol (1985) 96: 861-864.

31. Safdar A, Bourgeois JM, Ogborn DI, Little JP, Hettinga BP, et al. (2011) Endurance exercise rescues progeroid aging and induces systemic mitochondrial rejuvenation in mtDNA mutator mice. Proc Natl Acad Sci USA 108:
4135-4140.

32. Zhou W, Liu GH, Yang SH, Mi BB, Ye SN (2016) Lowintensity treadmill exercise promotes rat dorsal wound healing. J Huazhong Univ Sci Technolog Med Sci 36: 121-126.

33. Mizutani Y, Kanbe A, Ito H, Seishima M (2020) Activation of STING signaling accelerates skin wound healing. $J$ Dermatol Sci 97: 21-29.

34. Huen AC, Wells A (2012) The beginning of the end: CXCR3 signaling in late-stage wound healing. Adv Wound Care (New Rochelle) 1: 244-248.

35. Zhang Y, Thai K, Kepecs DM, Winer D, Gilbert RE (2018) Reversing CXCL10 deficiency ameliorates kidney disease in diabetic mice. Am J Pathol 188: 2763-2773.

36. Kanzleiter T, Rath M, Görgens SW, Jensen J, Tangen DS, et al. (2014) The myokine decorin is regulated by contraction and involved in muscle hypertrophy. Biochem Biophys Res Commun 450: 1089-1094.

37. Bhide VM, Laschinger CA, Arora PD, Lee W, Hakkinen L, et al. (2005) Collagen phagocytosis by fibroblasts is regulated by decorin. J Biol Chem 280: 23103-23113.

38. Puchert M, Adams V, Linke A, Engele J (2016) Evidence for the involvement of the CXCL12 system in the adaptation of skeletal muscles to physical exercise. Cell Signal 28: 1205-1215.

39. Guo R, Chai L, Chen L, Chen W, Ge L, et al. (2015) Stromal cell-derived factor 1 (SDF-1) accelerated skin wound healing by promoting the migration and proliferation of epidermal stem cells. In Vitro Cell Dev Biol Anim 51: 578-585.

40. Suganami T, Nishida J, Ogawa Y (2005) A paracrine loop between adipocytes and macrophages aggravates inflammatory changes: role of free fatty acids and tumor necrosis factor alpha. Arterioscler Thromb Vasc Biol 25: 20622068.

41. Ezure T, Amano S (2011) Negative regulation of dermal fibroblasts by enlarged adipocytes through release of free fatty acids. J Invest Dermatol 131: 2004-2009.

42. Ishiuchi-Sato Y, Hiraiwa E, Shinozaki A, Nedachi $T$ (2020) The effects of glucose and fatty acids on CXCL10 expression in skeletal muscle cells. Biosci Biotechnol Biochem 84: 2448-2457. 